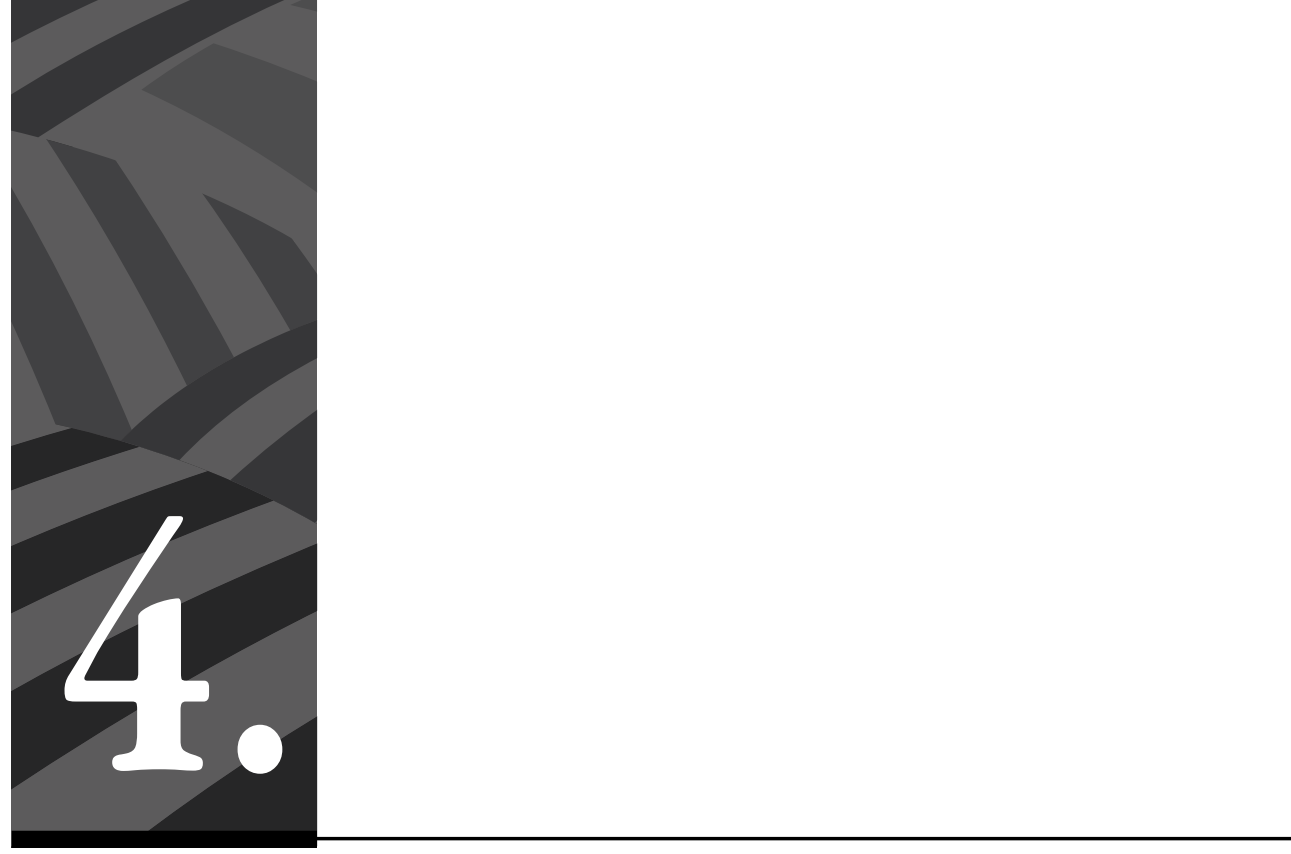

\title{
Aproximaciones al derecho a la verdad en la justicia transicional, en Colombia
}




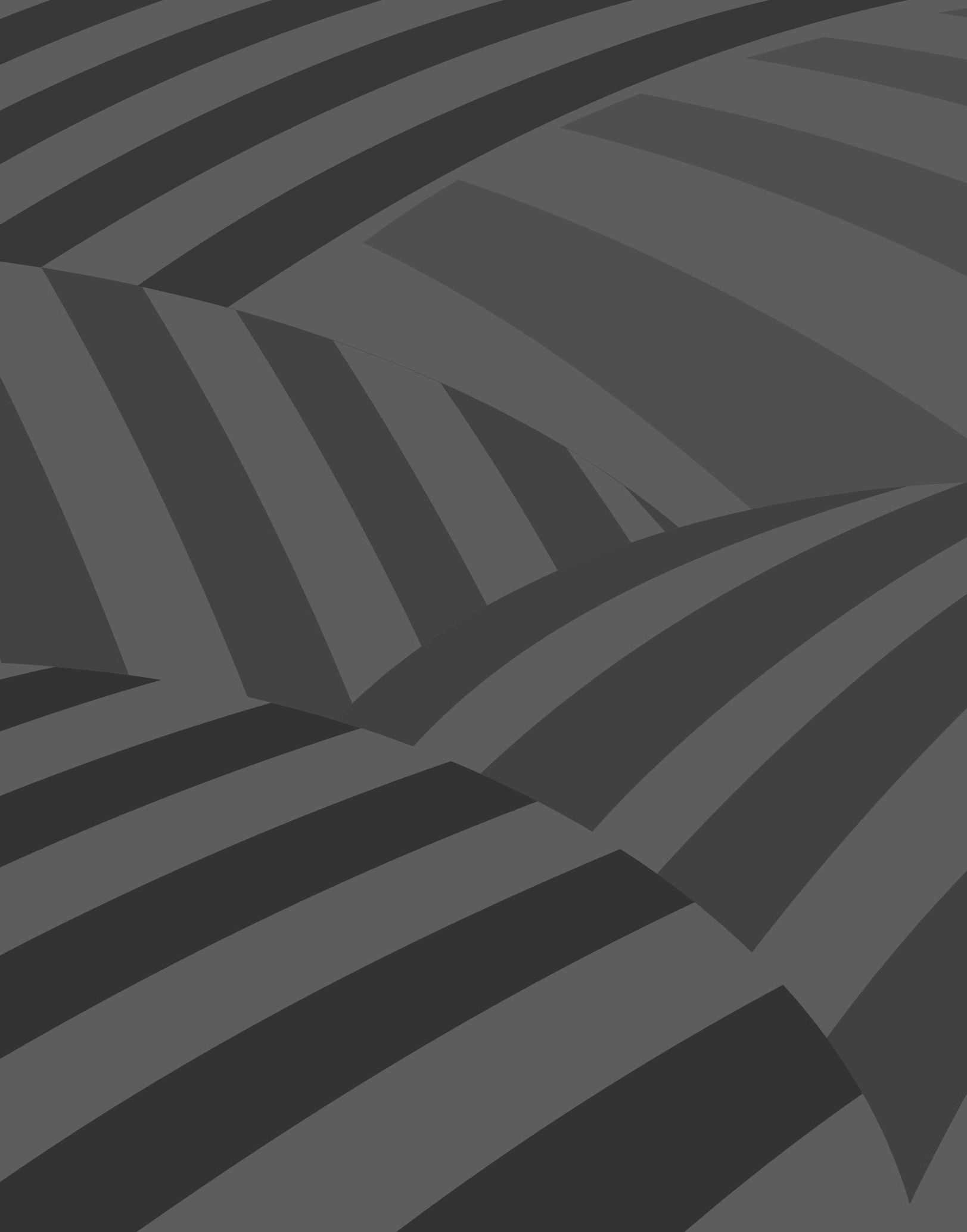




\section{Aproximaciones al derecho a la verdad en la justicia transicional, en Colombia}

Por Vera Samudio*, Alejandra Figueredo**

DOI: https://doi.org/10.54118/controver.vi217.1238

Resumen: La configuración de la verdad como el derecho a "saber qué ocurrió", es uno de los pilares fundamentales del sistema de justicia transicional implementado tras la firma del Acuerdo Final de Paz entre el Gobierno colombiano y las FARC-EP. En la verdad se ha depositado parte importante de la esperanza por la construcción de una paz estable y duradera, y de la reconciliación en el país. En el presente artículo se sostiene que el derecho a la verdad en el funcionamiento del Sistema Integral de Verdad, Justicia, Reparación y No Repetición (SIVJRNR) se experimenta como una construcción ética, jurídica, política y fáctica, que se desarrolla en el marco de un proceso relacional, multidireccional y polifónico, que va cambiando, modificándose y perfeccionándose en el tiempo, y puede pasar, según las necesidades y problemas a resolver, de tener un carácter puramente instrumental y racional, a uno ampliamente axiológico y moral. Para ello, se presenta una propuesta de operacionalización de esta verdad en respuesta a interrogantes sobre su comprensión: ¿Qué? ¿Cómo? ¿Para qué? ¿Cuándo? y ¿Quién?

Palabras clave: verdad, justicia transicional, Acuerdo Final de Paz, SIVJRNR.

\section{Approaches to the Right to Truth in Transitional Justice in Colombia}

Abstract: The truth's configuration as the right to "know what happened" has become one of the fundamental pillars of the transitional justice system implemented after signing the Final Peace Agreement between the Colombian Government and the FARC-EP. Thus, in truth, lays the hope for building a stable and lasting peace and reconciliation in the country. This article sustains that the right to the truth in the operation of the Comprehensive System of Truth, Justice, Reparation and Non-Repetition (SIVJRNR) is experienced as an ethical, legal, political and factual construction that is developed within the framework of a relational, multidirectional and polyphonic process.

* Abogada y MA en Estudios Políticos de la Universidad Nacional de Colombia, PhD en Procesos Políticos Contemporáneos de la Universidad de Salamanca-España. Investigadora del Cinep/Ppp. Correo electrónico: verasamudio@gmail.com

** Internacionalista de la Pontificia Universidad Javeriana, especialista en derechos humanos y derecho internacional humanitario de la Universidad Nacional de Colombia, candidata a MSc en Ciencias Políticas en la Universidad de Uppsala, Suecia. Correo electrónico: alejandra.figueredo@outlook.com 
This construction is changing, modifying and improving through time and can go, depending on the needs and problems to be solved, from having a purely instrumental and rational character to a broadly axiological and moral one. To this end, a proposal for operationalisation of this truth is presented in response to questions about its understanding: What? How? Why? When? and Who?

Keywords: Truth, Transitional Justice, Final Agreement, SIVJRNR.

Cómo citar este artículo: Samudio, Vera y Figueredo, Alejandra (2021). Aproximaciones al derecho a la verdad en la justicia transicional, en Colombia. Revista Controversia, 217, 121-162.

Fecha de recepción: 27 de febrero de 2021

Fecha de aprobación: 3 de mayo de 2021

\title{
Introducción
}

\begin{abstract}
In contextos de transición de la guerra a la paz, más allá del cese 4 de hostilidades y la reconstrucción de los escenarios destrozados por la violencia, los compromisos asumidos por las partes para el esclarecimiento de lo ocurrido son fundamentales para garantizar la estabilidad y continuidad en los esfuerzos de construcción de paz. Diversas experiencias de transición alrededor del mundo han encontrado en la verdad el epicentro de las posibilidades de paz, bajo la concepción que, del conocimiento que de esta se desprende, emanan transformaciones institucionales, políticas, económicas y culturales.
\end{abstract}

Esta idea del esclarecimiento de la verdad como medio indispensable para alcanzar la paz o llegar a regímenes más democráticos es relativamente nueva. Gracias a los desarrollos internacionales más recientes sobre los derechos de las víctimas y los límites que estos impusieron a los procesos de transición, el derecho a la verdad tomó fuerza y se incrustó en todos los mecanismos de exigibilidad de las víctimas, y en la normatividad desarrollada para la superación del conflicto armado en Colombia. 
En el ámbito jurídico, la verdad ha sido definida como el derecho "a saber lo que pasó, (...) que busca dar cuenta en forma amplia y detallada de lo que sucedió" (Rincón, 2010, p. 57) en contextos de conflicto armado y graves violaciones a los derechos humanos (DD. HH.) e infracciones al derecho internacional humanitario (DIH) (González-Salzberg, 2008; Uprimny y Saffon, 2006). Esta verdad se encuentra enmarcada dentro del concepto de justicia transicional, una justicia propia de procesos de transición que "mira tanto hacia el pasado como hacia el futuro" (Rincón, 2010, p. 26), y que va más allá de un proceso de justicia retributiva en torno a los crímenes cometidos.

Tras cuatro años de hacer seguimiento a la implementación del Acuerdo final para la terminación del conflicto y la construcción de una paz estable y duradera (Acuerdo Final, Acuerdo de Paz o Acuerdo), y en especial al punto sobre víctimas y justicia transicional, las autoras sostienen en este artículo que la verdad en el proceso de paz, entendida como el derecho a “descubrir o establecer la verdad de lo que pasó (quiénes fueron los autores, cómo actuaron, por qué hicieron lo que hicieron) y hacerla pública, para que las sociedades se apropien conscientemente de ella” (Rincón, 2010, p. 26), se experimenta como una construcción ética, jurídica, política y fáctica, que se desarrolla en el marco de un proceso relacional, multidireccional y polifónico, que va cambiando, modificándose y perfeccionándose en el tiempo, y puede pasar, según las necesidades y problemas a resolver, de tener un carácter puramente instrumental y racional, a uno ampliamente axiológico y moral.

Desde esta definición exploratoria propuesta por las autoras, es posible aproximarse a la operacionalización de la verdad mediante el análisis de cinco elementos: (1) El derecho a la verdad (iqué?); (2) la verdad en su realidad institucional y burocrática (¿cómo?), (3) la verdad funcional y finalista (ipara qué?); (4) la verdad en relación con sus tiempos (¿cuándo?); y, (5) la verdad a partir de quién la dice y quién la escucha (¿quién?), como se muestra en la figura 1. 
Figura 1. Elementos de operacionalización del derecho a la verdad

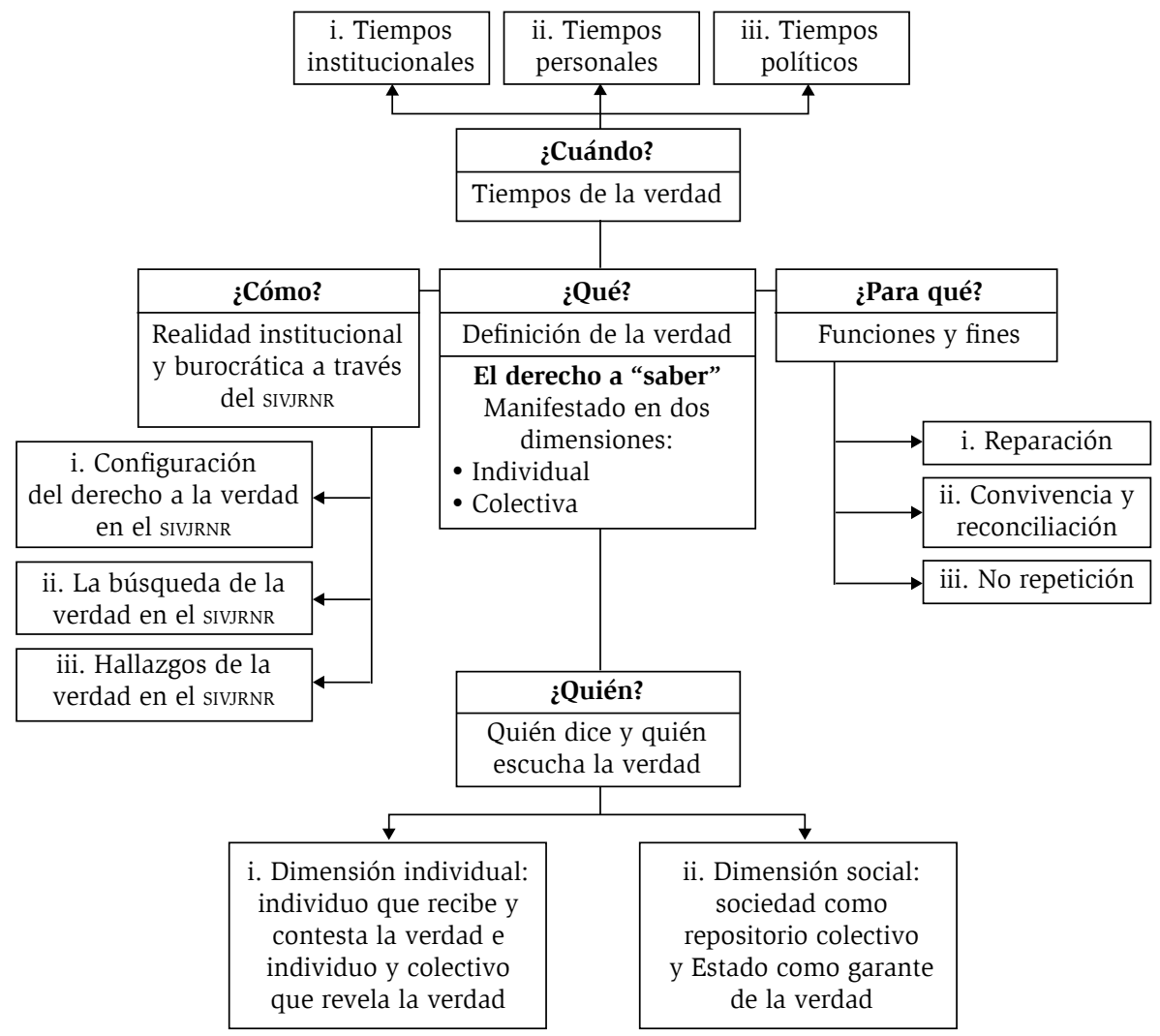

Fuente: elaboración propia.

En este artículo se abordan estas dimensiones a partir de lo observado hasta el momento en el ejercicio de seguimiento y verificación del punto 5 del Acuerdo Final, pero que, sabiéndose limitado por ser un ejercicio de análisis concomitante con los hechos de implementación, se plantea como hipótesis a revisar en el futuro mediato. 


\section{El ¿qué?: el derecho a la verdad en Colombia}

La definición del derecho a la verdad, es decir, "el derecho a saber", es resultado de los desarrollos históricos, jurídicos y conceptuales alcanzados en procesos transicionales posteriores a un conflicto armado. Su fundamento reside en el derecho inalienable de las víctimas y sus familiares a conocer información detallada sobre los hechos asociados a la violación de DD. HH. e infracciones al DIH sufridos en medio de las hostilidades. Busca esclarecer lo ocurrido, reparar los daños y garantizar que no vuelvan a ocurrir. Es por ello que guarda una cercanía intrínseca con el derecho a la justicia, en aras de garantizar la no impunidad, y el derecho a la reparación, como un mecanismo de satisfacción para las víctimas (Rincón, 2010).

Visto así, el derecho a la verdad cuenta con dos dimensiones: individual y colectiva. La primera, recoge el deber de garantizar a las víctimas el esclarecimiento con respecto a las violaciones sufridas en el marco del conflicto, es decir, una verdad factual, la cual involucra a receptores y reveladores de esta verdad, incluyendo responsables y testigos. La segunda, es el derecho de la sociedad a conocer esa verdad1 sobre los crímenes cometidos, siendo deberes del Estado los “de recordar y de proteger la memoria colectiva de actos propiciadores del olvido, el revisionismo o el negacionismo” (Rincón, 2010, p. 56).

Estos desarrollos normativos han impulsado que la verdad también se haya constituido en el núcleo de un importante conjunto de experiencias de justicias transicionales y comisiones de la verdad ${ }^{2}$, con múltiples

1 Una verdad con “dos dimensiones: factual, el relato de lo que ocurrió, y moral, la narración que busca explicar el porqué de lo ocurrido, y, en esa medida, configura un juicio crítico sobre los hechos” (Rincón, 2010, p. 55).

2 Las comisiones de la verdad son instrumentos legales creados en momentos de transición y cambios políticos para (i) "establecer los hechos acerca de eventos violentos que permanecen en disputa o son negados"; (ii) "proteger, reconocer y empoderar a las víctimas y sobrevivientes"; y (iii) "proponer políticas y promover cambios en el comportamiento de los grupos y las instituciones de un país con miras a una transformación política y social” (González y Varney, 2013, p. 13). 
resultados. En este grupo se puede encontrar la Comisión para la Verdad y la Reconciliación de Sudáfrica, inaugurada en 1995, tras el fin del régimen de apartheid, que promovió “el diálogo y el entendimiento” entre víctimas y perpetradores con una apuesta nacional de reconciliación; y la Comisión de la Verdad y Reconciliación de Perú, creada en 2001, que introdujo la aplicación de audiencias públicas y se enfocó en la reconstrucción del Estado (González y Varney, 2013; Comisión de la Verdad ${ }^{3}$ [CEV], 2018a).

En Colombia, la idea de la verdad, como eje central de la paz y la reconciliación, también ha tenido su génesis y recorrido en diversos procesos de paz que datan del siglo $\mathrm{xx}$, y ha encontrado su punto de mayor madurez en el Acuerdo Final firmado entre las FARC-EP y el Gobierno nacional en 2016. La mayoría de estos esfuerzos ${ }^{4}$ se enfocaron en la adopción de fórmulas jurídicas y políticas destinadas al desarme, desmovilización y reinserción (DDR), con el otorgamiento de amnistías e indultos para actores armados, y una visión de la justicia transicional como "un episodio de entrega de armas, perdón y olvido” (Samudio, 2019, p. 4).

Sin embargo, la lucha por el reconocimiento de los derechos de las víctimas, quienes durante varias décadas han trabajado en la generación de espacios de exigibilidad, presionó la adopción de desarrollos normativos más garantistas. La Ley 975 de 2005 que, a pesar de sus altibajos y controversias sirvió de marco para el proceso de “justicia y paz" con grupos paramilitares, y recogió, junto con su revisión constitucional mediante la sentencia C-370 de 2006, la importancia del reconocimiento

3 Su nombre completo es: Comisión para el Esclarecimiento de la Verdad, la Convivencia y la No Repetición.

4 Los acuerdos de La Uribe-Meta en los que se reconoció por primera vez a las FARCEP y a otras guerrillas como actores políticos; el proceso de paz con el M-19 que concluyó en su desmovilización y participación política en 1990; los procesos adelantados con el EPL, el Quintín Lame y el Partido Revolucionario de los Trabajadores (PRT); las negociaciones con la Corriente de Renovación Socialista entre 1993 y 1994; y el proceso fallido con las FARC-EP en San Vicente del Caguán, entre 1998 y 2002. 
de procesos de memoria, verdad y reparación a las víctimas del conflicto armado. Además, generó condiciones jurídicas para el enjuiciamiento y reincorporación a la vida civil de sus miembros, soportadas en una nueva institucionalidad. Posteriormente, la Ley 1448 de 2011, conocida como Ley de Víctimas, estableció las medidas de atención, asistencia y reparación integral a las víctimas del conflicto armado. También, creó entidades especializadas como la Unidad de Atención y Reparación a Víctimas (UARIV) y el Centro Nacional de Memoria Histórica (CNMH), al tiempo que planteó la necesidad de articular esfuerzos institucionales bajo un sistema nacional.

Todos estos procesos, con sus aciertos y fracasos, pavimentaron el camino hacia la consecución del actual Acuerdo Final, como una apuesta integral que no se limita a procesos de DDR, sino que pretende transformar las condiciones estructurales que dieron vía libre al conflicto armado durante más de cinco décadas. Se trata de un Acuerdo que, centrándose en las víctimas, tiene como uno de sus objetivos principales resarcirlas a través de la puesta en marcha de un Sistema Integral de Verdad, Justicia, Reparación y No Repetición (SIVJRNR).

Este Sistema Integral presenta una apuesta de justicia transicional en la cual es visible la complementariedad en sus componentes: (i) mecanismos judiciales y extrajudiciales que, en su conjunto, tienen como mandato principal la garantía de los derechos de las víctimas; (ii) la seguridad jurídica de los firmantes; (iii) la superación de la impunidad; y, por último, (iv) la generación de condiciones para promover la convivencia; estos elementos evitan la repetición de las atrocidades cometidas. En este caso, la verdad es eje central del modelo de justicia transicional, y en esta se depositan las mayores esperanzas para edificar un proceso sólido de reconciliación.

Sin soslayar lo que la justicia y la reparación significan en el marco de los derechos de las víctimas, la verdad, en el marco de la justicia transicional, se ha convertido en un punto central en la discusión actual en 
Colombia, abordada como uno de los derechos principales y, por tanto, como uno de los "límites normativos de la decisión política” (Rincón, 2010 , p. 25). La plena verdad a cambio de un modelo de justicia restaurativa, con sanciones propias y reparadoras distintas a la prisión, en la que sea posible descubrir las políticas, los planes, las estructuras y las responsabilidades institucionales y de los detentadores del poder. Una verdad que, finalmente, permita la identificación de los elementos que facilitaron el surgimiento y mantenimiento de las violencias, y que dé pistas ciertas sobre cómo evitar que se repitan.

En este compendio de mecanismos e instituciones que conforman el SIVJRNR, es posible identificar también diversas modalidades de la verdad que operan de forma conjunta en la "búsqueda” y realización de este derecho, complejizando a su vez su comprensión, y pueden nombrarse retomando los aprendizajes de la experiencia de transición sudafricana ${ }^{5}$, presentados por la Truth and Reconciliation Commission (1998), citada por Salazar (2015, p. 173), que se refieren aquí: una verdad narrativa, asociada a la “narración personal de relatos”, que se manifiesta en las versiones presentadas por víctimas y comparecientes ante el sistema; una verdad factual, enfocada en "reducir el número de mentiras”, y que emerge de un proceso de contrastación de las narrativas presentadas, algunas veces opuestas; una verdad social, que nace de la interacción en el proceso dialógico de esta justicia transicional, pues "instruye un modelo efectivo de diálogo poniendo cara a cara, pero sin confrontación, el relato de una víctima y el relato de un perpetrador”; y finalmente, una verdad reparadora que, más que a un tipo específico de narración, se refiere al potencial esperado de la realización del derecho

5 En el presente artículo se retoman las categorías de verdad implementadas en el proceso transicional de Sudáfrica, como instrumento hermenéutico para la aproximación analítica que se plantea en torno a este derecho. Si bien se reconoce que el caso surafricano ha sido analizado extensamente en la literatura de estudios de conflicto y paz — con autores que resaltan sus aprendizajes y avances, y otros más críticos en torno a la efectividad de satisfacción y reparación a las víctimas-, estos y otros debates al respecto no serán abordados aquí. 
a la verdad en la dignificación y reparación de las víctimas, así como en la reconstrucción de relaciones entre ciudadanos "en virtud de un valor curativo que se atribuye a la palabra”.

En el caso colombiano, se espera que la verdad resultante de este proceso sea una verdad contrastada y sujeta a una serie de preguntas, con el fin de comprobar su "sostenibilidad". Asimismo, limitar el alcance de "las falacias sobre las que ha estado montado el sistema en desarrollo, en las relaciones sociales, porque aquí hay muchos dolores y la gente ha dicho: 'si yo sé la verdad, yo puedo sanarme, yo puedo perdonar'” (Escuela Nacional Sindical, 2019, 46s). La verdad "debe realizar el análisis de las causas y sus consecuencias” (Makazaga, 2017, Una memoria, párr 3), su rol es el de esclarecer.

Sin embargo, esta verdad, lejos de emerger durante las transiciones como afirmaciones completas, únicas, atemporales, diáfanas y en versiones irrefutables, devienen oblicuas, complejas, intermitentes y multiformes. En realidad, es un componente altamente complejo de la realidad social, política y jurídica, al que se llega de múltiples formas, tiene variantes y matices, alcances e impactos.

A cuatro años de la firma del Acuerdo Final, y a cerca de tres del arranque formal del SIVJRNR, persisten muchos interrogantes alrededor de la verdad y su capacidad para cumplir con las expectativas que se han puesto en ella. Si bien este poder plural de la verdad está aún por establecerse, de los avances realizados hasta el momento por las entidades del Sistema ya es posible identificar aspectos reveladores de sus características y capacidades. 


\section{Las dimensiones de la verdad}

\subsection{El ¿cómo?: la verdad en su realidad institucional y burocrática}

Uno de los debates más intensos en las negociaciones de La Habana fue el de la justicia transicional. De allí surgió uno de los modelos más complejos hasta ahora diseñados en el mundo para garantizar los derechos de las víctimas y brindar seguridad jurídica a quienes participaron en el conflicto que, sin perder la guerra, negociaron la entrega de armas y su paso de la acción política militar a la acción política legal.

\subsubsection{La configuración del derecho a la verdad en el SIVJRNR}

Este modelo, abreviado en la sigla SIVJRNR (Sistema Integral de Verdad, Justicia, Reparación y No Repetición), vio la luz en el punto 5 del Acuerdo Final, compuesto por cinco mecanismos y medidas judiciales y extrajudiciales que recogen esfuerzos diversos para garantizar los derechos de las víctimas del conflicto armado, así como brindar condiciones de seguridad jurídica para los comparecientes, de manera que cumplan con su deber de aportar a una verdad exhaustiva, detallada y plena. Estos mecanismos son: la Comisión para el Esclarecimiento de la Verdad, la Convivencia y la No Repetición (CEV); la Unidad de Búsqueda de Personas dadas por Desaparecidas en el contexto y en razón del conflicto armado (UBPD); la Jurisdicción Especial para la Paz (JEP); las medidas para garantizar la reparación integral de las víctimas del conflicto en sinergia con la Ley de Víctimas existente (Ley 1448 de 2011); y las garantías de no repetición.

Se trata de un Sistema cimentado en un consistente andamiaje institucional, reglamentado por disposiciones de rango constitucional, aunque de carácter transicional, dotado de una sólida estructura normativa ${ }^{6} \mathrm{y}$

6 Normativa sobre el sIvJRNR disponible en https://juridia.jep.gov.co/normograma/ compilacion/normativa_sivjrnr.html 
una burocracia con alcance nacional. Con este modelo institucional, se espera alcanzar la verdad a partir de una simbiosis entre mecanismos judiciales y extrajudiciales que, con diferentes fórmulas —un proceso judicial transicional en su componente de justicia y uno metodológico en función del esclarecimiento de lo sucedido y la reconciliación mediante la investigación social y acciones para la convivencia, y la búsqueda de desaparecidos en sus componentes extrajudiciales-, permitan a las víctimas y a la ciudadanía aproximarse certeramente a la verdad. La articulación de estos mecanismos y medidas bajo un Sistema permite visibilizar la contribución de cada uno a la realización del derecho a la verdad, además del reconocimiento de los derechos de las víctimas, y las responsabilidades sobre los hechos y graves violaciones a los DD. HH. (Comisión de la Verdad y Dejusticia, 2019).

Para los componentes de “justicia” y “verdad” se concibieron en el Acuerdo mecanismos normativos e institucionales condensados en la JEP, en la CEV y en la UBPD respectivamente, que con posterioridad fueron incorporados en la Constitución por el Congreso de la República, y revisados por la Corte Constitucional. Igualmente, se diseñaron rutas metodológicas con alcance en los territorios para avanzar en el cumplimiento de sus objetivos ${ }^{7}$. Cada entidad incluyó dentro de su mandato el objetivo de alcanzar la verdad, entendiéndola de diversas maneras y abordándola con diferentes metodologías, pero en el reconocimiento de que esta se construye en el contraste de múltiples fuentes y la corroboración de la veracidad de la información obtenida. Así, es posible encontrar diversas modalidades de la verdad operando conjuntamente, mediante elementos narrativos, judiciales, sociales y reparadores.

Por un lado, se encuentra una verdad narrativa, que recoge el principio de participación de las víctimas del conflicto en todos los procesos que adelanta el SIVJRNR con sus aportes y observaciones, así como el

7 Lineamientos metodológicos. Escuchar, reconocer y comprender para transformar, en el caso de la CEV y el Plan Nacional de Búsqueda, en la UBPD. 
deber de los comparecientes de contribución con una verdad plena y detallada. Por otro lado, existe una verdad factual que emerge de un proceso de contrastación, confrontación y verificación de las narrativas presentadas, cuyo resultado se puede asociar a los provenientes de procesos judiciales que configuran conductas y decisiones sobre los sujetos procesales involucrados en los casos adelantados por la JEP, y a las investigaciones y búsquedas humanitarias de personas dadas por desaparecidas que adelanta la UBPD, recolectando y comparando datos provistos por víctimas, comparecientes y la institucionalidad competente ${ }^{8}$.

Ambas modalidades recogen la labor general que realiza el Sistema de recolección y contrastación de información con fines específicos, y se relacionan con una verdad social que materializa los objetivos de convivencia y reconciliación que subyacen al SIVJRnR. Por consiguiente, se espera que emerja una verdad social capaz de reconocer y visibilizar los hechos que ocurrieron en el conflicto, al tiempo que permita la comprensión de diversos puntos de vista y experiencias. Asimismo, la verdad en su modalidad reparadora o curativa se presenta como un “aporte a la dignificación y reparación de las víctimas” (Moreno, 2017, p. 10) y a la reconstrucción de relaciones entre ciudadanos.

De esta forma, si bien la verdad factual que persigue la JEP se busca, por cuanto se hace necesaria para acometer los procesos de investigación y sanción a los responsables, condensada en las decisiones tomadas por la Jurisdicción en torno a los casos priorizados, en las otras modalidades de verdad de corte narrativo, social y reparador, la verdad se sitúa como fin en sí mismo, pero con diferentes alcances y contenidos.

\subsubsection{La búsqueda de la verdad en el SIVJRNR}

El compareciente ante el SIVJRNR llega a aportar a la verdad de forma voluntaria, entendiendo que combatientes de la antigua guerrilla de las

8 Artículo 5.b, Decreto 589 de 2017, que crea la UBPD. 
FARC-EP y el Estado colombiano participaron y aprobaron lo pactado. Sin embargo, una vez se someten a la JEP se instala un régimen de condicionalidad, mediante el cual los beneficios de la justicia restaurativa y la transicionalidad del Sistema quedan directamente ligados a sus aportes a la verdad. Una verdad que se entiende plena, y que debe ser proporcionada de forma completa, detallada y exhaustiva. En todos los casos se trata de una verdad que debe superar con creces lo conocido ya por la justicia ordinaria y otras justicias transicionales. Por tanto, se exige del Sistema un mayor esfuerzo en la cantidad y calidad de la información recopilada.

Con este propósito, se posicionan las narraciones en torno al conflicto, en diferentes formatos - oral, escrito o audiovisual-, y en respuesta a los mandatos y procesos adelantados por cada una de las entidades. Ejemplo de ello es la recolección y análisis de testimonios individuales y voluntarios de las víctimas y comparecientes ante la CEV (2021b), y los casos presentados para alcanzar el esclarecimiento de los hechos cometidos en el marco del conflicto; también están los aportes voluntarios (documentales) hacia la UBPD (2020a) como contribución a la búsqueda y localización de personas dadas por desaparecidas; y el deber de rendir versiones individuales y colectivas por parte de los comparecientes ante la Sala de Reconocimiento de Verdad y Responsabilidad de la JEP (SRVRJEP), con el fin de otorgar "verdad plena” sobre los hechos y conductas ocurridas en el marco del conflicto.

A partir de las distintas narraciones se hace posible el ejercicio de comparación y contrastación institucional en búsqueda de una verdad factual en el SIVJRNR. Ello es posible a partir del análisis, la interpretación y la generación de inferencias de las fuentes testimoniales y documentales recibidas, que pueden traducirse en un informe final de esclarecimiento o en planes regionales de búsqueda. En el caso particular de la JEP, también resulta de los debates provenientes de la presentación de observaciones de las víctimas a las versiones rendidas por los comparecientes, 
en virtud del proceso dialógico establecido en un primer momento en la JEP, o en la contienda judicial propia del proceso adversarial ${ }^{9}$.

Vinculada a la verdad narrativa y factual se encuentra su modalidad social, enfocada en el proceso de construcción dialógica ${ }^{10}$ y conjunta de la verdad, en la cual se encuentran las versiones de los diferentes actores partícipes en el conflicto. Sea a través de un Encuentro por la Verdad $^{11}$ o de un Diálogo Social y Encuentro de Convivencia ${ }^{12}$ en el marco del mandato de la CEV, lo relevante en este punto es el encuentro entre visiones y comprensiones sobre el conflicto, que permiten un diálogo sin confrontación, un reconocimiento del otro. Estos espacios de interacción, en los cuales es posible alcanzar una verdad social, contribuyen, además, a la identificación de patrones y causas explicativas del conflicto armado interno con el fin de promover el reconocimiento y la satisfacción del derecho a la verdad de las víctimas y de la sociedad.

De cualquier forma, se espera que estos aportes, en complemento de las facetas judiciales y extrajudiciales de la verdad, conduzcan al reconocimiento y dignificación de las víctimas y ofrezcan un alcance reparador

9 El artículo 27B de la Ley 1922 de 2018 establece el deber de "contrastar la información” recibida por la SRVR-JEP, en su procedimiento de construcción dialógica de la verdad. El artículo 27D de la Ley 1922 de 2018 establece las condiciones de participación de las víctimas, presentando pruebas u observaciones a las versiones voluntarias.

10 Figura procesal establecida en el artículo 27 de la Ley 1922 de 2018 para contribuir al principio de justicia restaurativa de la JEP.

11 Mecanismo metodológico de la CEV para el cumplimiento del objetivo de esclarecimiento. Diálogos públicos o privados para que responsables en el marco del conflicto puedan "contribuir al esclarecimiento de la verdad y de hacer actos de reconocimiento frente a las víctimas y las comunidades" (CEv, 2019, p. 20).

12 Mecanismo metodológico de la CEv para el cumplimiento del objetivo de reconocimiento. "Encuentro de sectores sociales, políticos y económicos que tengan experiencias distintas e incluso contrarias sobre el conflicto armado interno, para el análisis crítico sobre su participación directa o indirecta en lo que ocurrió en su territorio" (CEv, 2019, p. 27). 
al evitar el olvido sobre lo ocurrido y permitir el cierre de ciclos de violencia, es decir, no repetición. Este compromiso es visible, por ejemplo, en la labor humanitaria de la UBPD en la búsqueda de personas dadas por desaparecidas, centrado en las familias de las víctimas y su participación en los diferentes momentos del proceso.

Cabe agregar que la conjugación de componentes judiciales y extrajudiciales del SIVJRNR permite “aportar facetas de la verdad, por ejemplo, sobre causas de las violaciones o responsabilidades políticas por las mismas, que no es el objetivo de los procesos penales" (Moreno, 2017, citada en ICTJ, 2017, El derecho a la verdad es inalienable, párr. 7 ), que complementen a la verdad factual, y determinen condiciones para la no repetición de la violencia y la reconciliación, a partir del reconocimiento de hechos y responsabilidades, que eviten el olvido de los crímenes cometidos.

\subsubsection{Los primeros hallazgos de la verdad en el SIVJRNR}

Ciertamente, cada entidad de este Sistema presenta en la actualidad diferentes niveles de avance en su propósito de llegar a la verdad, relacionados con sus tiempos de mandato, capacidades institucionales y objetivos. La CEV se encuentra ad portas de presentar su informe final, en el que pretende establecer hechos y explicaciones verídicas a partir de contextos explicativos y patrones, y en el cual se espera que se incluyan análisis e información en torno a los núcleos de conocimiento establecidos que orientan la investigación realizada ${ }^{13}$, así como recomendaciones que guíen los cambios necesarios para la no repetición. La UBPD continúa en

13 (i) Responsabilidades del Estado, (ii) Dinámicas económicas, despojo, desplazamiento y conflicto armado; (iii) Actores armados y otros responsables en las dinámicas de la guerra; (iv) Economía de las drogas ilícitas y conflicto armado; (v) Dimensiones internacionales y exilio; (vi) Causas, dinámicas e impactos del conflicto armado en pueblos étnicos; (vii) Afrontamientos, resistencias no violentas y transformaciones para la paz; (viii) Sociedad y cultura; (ix) Democracia y conflicto armado (CEV, 2020, p. 27). 
su proceso de búsqueda con resultados parciales ${ }^{14}$ y la JEP avanza en siete macrocasos en los cuales han sido acreditadas 307490 víctimas $^{15}$ (JEP, 2020 , p. 28), de los cuales dos (001 y 003) se encuentran en etapa de escritos de hechos, reconocimiento y resolución de conclusiones.

Según la Secretaría Técnica del Componente Internacional de Verificación CINEP/PPP-CERAC (2021), estos avances han venido acompañados por retos asociados al "deterioro de la seguridad en los territorios y los ataques políticos y mediáticos -especialmente a la JEP y a la CEV-” (p. 13) y la pandemia CoviD-19, los cuales "se constituyeron en obstáculos para el cabal desarrollo de su mandato” (p. 13). No obstante, a la fecha de cierre de este artículo se comienzan a identificar los primeros resultados en materia de verdad. La antigua guerrilla de las FARC-EP ha asumido la responsabilidad de numerosos homicidios, entre ellos el del líder conservador Álvaro Gómez Hurtado. Además, se empieza a conocer parte de la magnitud de la desaparición forzada a partir del trabajo de la JEP, en el marco de las medidas cautelares en cementerios y fosas comunes; la Comisión de Búsqueda de Desaparecidos - Componente FARC comenzó a recolectar al interior de sus miembros información sobre personas desaparecidas que ha trasladado a la UBPD; y varios políticos y expresidentes han participado en diálogos con la $\mathrm{CEV}^{16}$.

A nivel regional numerosas víctimas han logrado presentar versiones sobre los hechos del conflicto. También, terceros y miembros de la fuerza pública han tenido la oportunidad de presentar sus relatos de victimización. De manera particular, ya se conoce el primer auto sobre

14 Ha recibido 9058 solicitudes de búsqueda y 14 planes regionales de búsqueda en marcha (stciv, 2021).

15 Información a corte del primer semestre de 2020.

16 Sobre los avances del SIVJRNR, consultar los informes de la Secretaría Técnica del Componente de Verificación Internacional, disponibles en: https://cinep.org.co/ Home2/temas/verificacion-internacional/secretaria-tecnica.html 
hechos y conductas relativas al secuestro ${ }^{17}$, que permite avanzar en la comprensión de la magnitud de este fenómeno en el país y augurar avances sobre los demás casos.

Precisamente en este proceso institucional y burocrático la verdad se descubre rugosa, discontinua, interrumpida y compleja. Las narrativas de los intervinientes resultan parciales, incompletas y cargadas de sentidos subjetivos, algunos con evidente sinceridad, otros en perfecta adaptación a la estrategia judicial. Mezclados con las versiones, los hechos aparecen esquivos, la mayoría reposando en miles de folios y carpetas de expedientes viejos, debiéndose desplegar por parte de los funcionarios toda suerte de investigaciones técnicas y científicas para verificarlos. En estos procesos burocráticos también los muertos comienzan a hablar a través de las prospecciones y exhumaciones, los comparecientes hacen lo propio entre diligencias judiciales, y las víctimas con sus informes, preguntas y observaciones buscan rellenar los vacíos y las grietas que van dejando los relatos de los responsables. Solo de este forcejeo surgen las primeras conclusiones y se empieza a esbozar la verdad.

\subsection{El ipara qué?: la verdad funcional y finalista}

La verdad que emerge como resultado del trabajo burocrático e institucional es un derecho que, además de ser autónomo, es reconocido también en función de otros derechos y fines. La implementación del SIVJRNR ha ayudado a comprender otras tareas de la verdad relativas al derecho a la reparación y a la convivencia, la reconciliación y la no repetición.

17 Auto N. ${ }^{\circ} 19$ de 2021 de la SRVR-JEP, por medio del cual determinan los "hechos y conductas atribuibles a los antiguos miembros del Secretariado de las FARC-EP” en relación con el Caso 001 "Toma de rehenes y graves privaciones de la libertad cometidas por las FARC-EP”. 


\subsubsection{La verdad en su función reparadora}

La verdad reivindica el sufrimiento de las víctimas y las dignifica. Aquí, el foco de atención se traslada del hecho violento a la víctima, proporcionándole a esta la información sobre lo ocurrido como medida de satisfacción. En el caso de la desaparición forzada, el conocimiento del paradero de la víctima es un mecanismo de reparación.

En Colombia esta función se amplifica al menos por dos razones. En primer lugar, hay un margen amplio de asuntos que permanecen ocultos, aunque existe un conocimiento acumulado sobre el conflicto y varios de los hechos más violentos que han ocurrido con ocasión de este. El esclarecimiento de patrones y políticas criminales, así como la responsabilidad de las élites políticas y económicas del país en el desarrollo de las confrontaciones, son deudas históricas y de gran valor para las víctimas. A su vez, el conocimiento de hechos particulares y concretos relativos a los crímenes individuales es mínimo, y los avances de la justicia ordinaria en el esclarecimiento de la verdad son bajos. De ello dan cuenta los niveles de impunidad que han existido en el país, y que han dejado a millones de personas sin conocer aspectos específicos de la verdad de su caso. Para la víctima y su familia, conocer las razones y pormenores de su caso representa un alivio y una dignificación reparadora.

En segundo lugar, el valor de la verdad como elemento reparador se incrementa porque las nuevas entidades del Sistema no están habilitadas para proporcionar indemnizaciones económicas, recayendo esta función casi que exclusivamente en las medidas de reparación administrativa construidas una década atrás. Es necesario señalar que, en Colombia, sin detrimento de las decisiones que toma eventualmente la justicia ordinaria e internacional al respecto, los mecanismos de reparación individual y colectiva recaen en la UARIV, entidad creada hace diez años, adscrita al Ejecutivo, que aunque normativamente ha significado 
un avance en términos de reconocimiento de los derechos de las víctimas, también ha sido ineficiente en su aplicación ${ }^{18}$.

Esta situación abre un debate necesario en relación con la capacidad reparadora de la verdad y la satisfacción de las víctimas, más allá de su enunciación formal y abstracta. Esto lo entendieron los firmantes del Acuerdo Final al incluir dentro del SIVJRNR el fortalecimiento de la política de atención y reparación a víctimas, y su adecuación a este modelo de justicia transicional. También generó dispositivos para que la reparación funcionara, independientemente de la reparación proveniente de la verdad. El régimen de condicionalidad, la entrega de un inventario de bienes de las FARC-EP con destino a un fondo para la reparación, la creación de los trabajos, obras y actividades con contenido reparadorrestaurador (TOAR) y las sanciones propias, entre otras, son fórmulas que buscan la realización integral de los derechos de las víctimas.

Sin embargo, las discusiones sobre el nivel de verdad y la satisfacción en las contribuciones realizadas por los responsables han sido frecuentes entre las víctimas acreditadas ante la JEP y quienes han proporcionado información a la CEV y a la UBPD. Algunas víctimas han exigido, por ejemplo, mayor reconocimiento por parte de los responsables en el macrocaso de reclutamiento forzado contra las FARC-EP o en el de "falsos positivos” contra militares. Además, se han quejado por la falta de acciones de la UBPD en relación con la búsqueda de sus familiares, o temen que sus relatos no queden incluidos en el informe de la CEv, mientras otras víctimas mantienen su confianza en que, en el momento debido, la verdad emanará en los diferentes procesos que adelanta el SIVJRNR.

18 Consultar Séptimo informe de la Comisión de Seguimiento y Monitoreo a la Ley 1448/2011. Disponible en: https://www.procuraduria.gov.co/iemp/ media/file/img/noticias/S \% C3 \% A9ptimo \% 20Informe \% 20sobre \% 20la \% 20 implementaci \% C3 \% B3n \% 20de \% 20la \% 20Ley \% 20de \% 20V\% C3 \% ADctimas \% 20 y\%20la \%20Resti .pdf 
Aún es pronto para conocer si estos dispositivos de reparación contribuirán a la realización del derecho a la verdad de las víctimas. También, es temprano para conocer los grados de satisfacción de las víctimas con las verdades que van emergiendo del trabajo del SIVJRNR. Lo que sí es claro por el momento es que la verdad, si bien resulta necesaria y pertinente, no agota las expectativas de las víctimas, quienes de tiempo atrás vienen desarrollando procesos colectivos de denuncia y exigibilidad por su reparación integral.

\subsubsection{El rol de la verdad como puente para la convivencia y la reconciliación}

El principio de la reconciliación como fin de las negociaciones, y en particular en el Acuerdo Final sobre las víctimas del conflicto, fue recogido desde la Declaración de principios para la discusión en torno al punto 5 "Víctimas"19. Allí, la reconciliación se comprende como uno de los objetivos de la satisfacción de los derechos de las víctimas, que conduce a caminos de civilidad y convivencia. Siguiendo esa línea, la verdad también ha sido considerada como un elemento propiciador de la reconciliación y la convivencia. En este caso, la confianza, que se ve reconstruida a través de la verdad y el reconocimiento de las responsabilidades, se convierte en un factor necesario para la construcción de la paz. También en este caso, a nivel internacional se reconoce la verdad como un elemento fundamental para la reconciliación, el cual se esgrime como el fin deseado tras un conflicto.

Esta idea de la reconciliación y su enlace con la verdad fue concretada en Colombia, a partir de la inclusión de la promoción de la convivencia como uno de los objetivos de la CEV en el Acuerdo Final. Así, esta entidad también tiene un deber con la promoción de la convivencia, a partir de la creación de ambientes transformadores en los que sea posible la resolución pacífica de conflictos y la construcción de una cultura

19 Disponible en https://www.youtube.com/watch?v=6P_Pm1dYrWA 
del respeto y la tolerancia. Estos objetivos contribuirían a sentar las bases de la reconciliación, la no repetición y la construcción de una paz estable y duradera.

Sin embargo, este objetivo no está tan cerca de cumplirse aún. Por el contrario, actualmente el país mantiene una seria fractura política e ideológica, de la que se conoció su dimensión en el resultado del plebiscito que perdió el gobierno Santos, y que se viene reforzando en cada contienda electoral. A esto se suma una guerrilla activa, y numerosos grupos paramilitares y de violencia organizada que atentan diariamente contra la integridad y convivencia de las comunidades.

No obstante, las entidades del Sistema han dado algunos pasos importantes. La CEV realiza un esfuerzo permanente en los territorios para desarrollar actividades que permitan el acercamiento entre las víctimas, las comunidades y los responsables, como los diálogos multiactor. En algunos casos individuales, a partir de la recepción de testimonios se ha abierto la posibilidad para escuchar los reconocimientos de responsabilidad sobre el secuestro y su gravedad por parte de los responsables, y comenzar lentamente a sanar heridas. También, la antigua guerrilla de las FARC-EP, ahora Partido Comunes, ha desarrollado acciones de reconocimiento de responsabilidades que le han permitido acercarse a las víctimas y avanzar en la construcción de escenarios de convivencia. En cualquier caso, este aspecto de la verdad aún es incipiente y seguramente requerirá décadas de trabajo para que alcance un nivel significativo de consolidación.

\subsubsection{La verdad en lógica de creación de condiciones para la no repetición}

La verdad también es importante para entender cuáles fueron los dispositivos sociales, políticos y económicos que permitieron la acción violenta. En particular, entender los factores subyacentes que incidieron en la producción de los hechos es una condición indispensable 
para identificar cuáles son los cambios que se requieren desarrollar para evitar que se produzcan nuevamente. Esta garantía de no repetición se asumió en Colombia como el resultado de la implementación integral del Acuerdo.

Vistos en su conjunto, los temas abordados en el Acuerdo Final son el resultado de la explicación que construyeron las partes durante las negociaciones sobre el surgimiento del conflicto. Bajo este supuesto, solo la superación de las problemáticas expuestas allí mediante la adecuada implementación del Acuerdo, permitiría subsanar los problemas de base que causaron el inicio y mantenimiento del conflicto, evitando su repetición.

Pero también los negociadores incluyeron medidas específicas de no repetición en el punto 3 "Fin del Conflicto" y en el punto 5 "Acuerdo sobre las Víctimas del Conflicto”, y señalaron que las entidades del Sistema, en el desarrollo de sus mandatos, contribuirían también a garantizar la no repetición. En especial, asignaron a la CEV el deber de incluir en su informe final recomendaciones de su trabajo con este fin. En lo que atañe a este aspecto, estas recomendaciones, que además se están construyendo de manera participativa, podrían convertirse en las bases para la generación de cambios institucionales, políticos, económicos y culturales de orden estructural, orientados a la no repetición.

Ad portas de presentarse a la opinión pública el informe de la CEV, han sido múltiples los debates sobre el contenido de estas recomendaciones. Los temas; los aspectos institucionales, políticos, económicos, sociales y culturales que pretendan tocar; y los cambios que deben proponerse, son fuente de múltiples discusiones y requieren de sendos análisis y evaluaciones. En cualquier caso, la capacidad de implementar dichas recomendaciones es, a juicio de este análisis, un elemento fundamental para su contribución a la no repetición. 
De estas recomendaciones se espera una agenda de futuro no sobre el deber ser, sino sobre la ruta a seguir, con propuestas concretas que tengan la capacidad y la ambición de romper atavismos y empujar cambios. Ello implica determinar los actores involucrados en la toma de decisiones y en la promoción de los cambios, los escenarios, las dinámicas, los tiempos y las tensiones. También es necesario fijar la atención en la composición, credibilidad y nivel político del Comité de Seguimiento de estas recomendaciones. Su capacidad y grado de influencia serán decisivos para evitar que los esfuerzos por la no repetición, resultado de estas recomendaciones, no sean infructuosos.

\subsection{El ¿̇cuándo?: la verdad en relación con sus tiempos}

Al hablar de tiempos en la verdad se confrontan tres experiencias paralelas: los tiempos de los mandatos, los tiempos individuales y los tiempos políticos.

En primer lugar, se encuentran los tiempos establecidos para la implementación de los mandatos de cada entidad del Sistema, vinculados con la realidad institucional de la búsqueda de la verdad. Mientras la CEV cuenta con tres años, la UBPD tiene una duración de veinte años prorrogables, la JEP ejercerá sus funciones por un período de quince años - extendibles hasta veinte-, y las medidas de reparación, tras la sentencia C-588 de 2019 de la Corte Constitucional, tendrán una vigencia hasta 2031 en el marco de la Ley 1448 de 2011.

Esta variación entre los diferentes períodos de implementación responde a la naturaleza particular de los componentes del Sistema. Cada uno de los procesos que adelantan estas entidades, ya sea a través de la recolección de testimonios y entrevistas; la generación de espacios de reconocimiento, perdón y reconciliación; la investigación y prospección para la búsqueda de desaparecidos con la complejidad técnica que ello entraña; o el inicio de procesos de enjuiciamiento y sanción a responsables del conflicto, 
requiere tiempos específicos para su contribución al esclarecimiento de la verdad y la construcción de paz. También en el proceso de construcción dialógica de la verdad, los comparecientes ante el SIVJRNR deben cumplir con unos tiempos estipulados para su sometimiento e intervención ante las entidades, supeditados a su vez por el régimen de condicionalidad para el otorgamiento de tratamientos especiales ante la justicia, que les obliga a atender al llamado a contribuir con la verdad cuando sean requeridos.

En segundo lugar, se encuentra la experiencia de tiempos propia de los individuos y los procesos de duelo, rehabilitación, sanación y aceptación de lo vivido, tanto en las víctimas como en los comparecientes. Para las víctimas, pareciera que el "único tiempo disponible puede bien ser el presente: el presente del drama que acaba de irrumpir o que irrumpió tiempo atrás pero que sigue siendo para la víctima su único presente” (Hartog, 2012, p. 15). Un presente que en ocasiones parece permanente. Para los responsables el tiempo se prolonga o retrae con los rituales jurídicos y exigencias legales, se vuelve insondable en los olvidos reales exigidos por la crudeza del conflicto, o simulados por conveniencias judiciales o antiguos pactos de silencio. El tiempo también se puede extender indefinidamente esperando que vengan otros, testigos o cómplices, a completar el rompecabezas de la verdad, o se relaciona con la percepción de seguridad - física y legal- que tengan los involucrados, lo cual va marcando el ritmo para complementar y brindar más información sobre su experiencia de conflicto.

Así, la justicia transicional, desde sus diversos mecanismos, "se despliega entre un antes y un después, creando así un tiempo intermedio” (Hartog, 2012, p. 15), con el cual se pueden edificar puentes entre el pasado y el futuro. Ello se logra a partir del intercambio y encuentro entre víctimas y responsables, en la búsqueda del esclarecimiento y reconocimiento frente a lo ocurrido, sentando las bases para la no repetición y permitiendo que el tiempo marche nuevamente hacia una transformación. Partiendo de la experiencia emocional que afrontan las vícti- 
mas desde el momento en el cual sus derechos son transgredidos, y en respuesta de sus expectativas, la justicia transicional no solo recoge el recuento de lo ocurrido, sino que les brinda un nombre, en el marco del derecho penal nacional e internacional, reafirmando así su gravedad.

Por último, la verdad se encuentra atravesada por los tiempos políticos de la transición entre el fin del conflicto y la construcción de paz. Ello tiene sentido bajo la comprensión del derecho a la verdad como un constructo que deriva de un proceso político que se modifica y transforma en el tiempo. Por tanto, se puede afirmar que a partir de los tiempos de implementación del SIVJRNR es posible "la constitución de sujetos, de estructuras, de culturas y de procesos políticos” (Tapia Mealla, 2009, p. 18), que permiten una interacción y finalmente la consolidación de la verdad y la transición hacia la paz.

Los tiempos políticos ${ }^{20}$ vinculados a la búsqueda de la verdad permiten (i) la constitución de sujetos, estructuras, historias y relaciones, tanto a nivel normativo como en su puesta en marcha, ejemplificadas en la creación misma del SIVJRNR; (ii) el encuentro, conocimiento y [re]conocimiento entre estos organismos y actores, a partir de rituales diseñados con procedimientos específicos tanto judiciales como extrajudiciales, en los cuales se permite la "intersubjetividad, más o menos conflictiva, más o menos cooperativa” (Tapia Mealla, 2009, p. 23) y la construcción conjunta de la verdad; y (iii) la condensación y articulación de espacios políticos en los que se construyen vínculos de confianza y se abre paso al fortalecimiento del capital social, que permite acciones colectivas hacia la construcción de paz. La convergencia de diversas esferas de la vida social y las experiencias del conflicto, con sus expresiones de organización y participación o resistencia, dan origen a iniciativas encaminadas hacia la convivencia y la no repetición. En este sentido, se

20 Dimensiones y concepción de espacio-tiempos en la vida política, en la que convergen relaciones, territorios y procesos de transformación (Tapia Mealla, 2009). 
puede apreciar la verdad y su rol en los tiempos que requiere la transformación y transición hacia la paz.

Estos tres tiempos superpuestos se abren paso en la experiencia concreta de la implementación del Acuerdo. El SIVJRNR se encuentra constantemente en un "ir y venir" en el proceso de búsqueda de la verdad, en el que convergen expresiones institucionales, personales y políticas de la temporalidad en la que se implementa el Acuerdo Final. Esclarecer la verdad, en cualquiera de las entidades del Sistema, implica la realización de una serie de pasos con los cuales se espera generar el suficiente número y calidad de contrastaciones de diferentes versiones que permitan llegar a una conclusión satisfactoria de lo ocurrido. Estos pasos están previamente caracterizados y normados, obedecen a unas reglas y principios, tienen unos tiempos previstos o previsibles y un cierre: la sentencia del macrocaso, el informe final, el hallazgo de un desaparecido. Su objetivo final es permitir el cierre de ciclos de violencia, abriendo paso al conocimiento y recuerdo sobre lo ocurrido, contrarrestando el flagelo del olvido.

No obstante, la implementación del punto 5 del Acuerdo ha mostrado que el aporte a la verdad que se espera de los comparecientes, y sobre la cual reposa la posibilidad de mantenerse en el SIVJRNR, no se produce en un solo acto, versión o evento. Durante tres años, en cada una de las instancias, se han desarrollado numerosos eventos/audiencias en los que los comparecientes presentan sus aportes a la verdad, algunos de manera general y pública, otros de forma específica y reservada, dependiendo de las reglas y procedimientos estatuidos y las decisiones de los comparecientes. En este contexto, las víctimas, lejos de ser sujetos pasivos, se convierten en protagonistas del relato de los responsables, en algunos casos indagando por los detalles de los hechos, en otros casos desacreditando las versiones ${ }^{21}$.

21 En la JEP, las víctimas presentaron 272 observaciones a las versiones de los excombatientes de las FARC-EP en el marco del Caso 001 (JEP, 2020), y familiares de 
Siendo reconocibles los tiempos institucionales en la búsqueda de la verdad, iqué ocurre con los tiempos humanos e individuales? La construcción o reconstrucción de la verdad también pasa por unos tiempos individuales o colectivos que responden a la psique humana y a la evolución particular del duelo, la aceptación o negación frente a lo ocurrido, y la decisión franca y libre de expresarla. Ello se presenta no solo desde el lado de las víctimas, quienes reclaman con urgencia respuestas, sino también de los comparecientes y los aportes que deben realizar. En el caso de estos últimos, es clara su responsabilidad y obligación de aportar la versión factual de los hechos. Sin embargo, es en la interlocución propiciada por el sIVJRNR, y en particular desde los procesos dialógicos en la SRVR-JEP, en donde se puede ver la secuencia de los aportes, sus transformaciones, y los momentos en los que la verdad va emergiendo. Aunque, ¿cuántos momentos se demandan para llegar a la verdad factual?, o icuánto tiempo requieren los comparecientes para revelar sus relatos?, son asuntos que permanecen sin respuesta, y que podrían ser problematizados considerando los tiempos limitados para este propósito en este Sistema. La burocratización y las funciones atribuidas a la verdad, así como el profundo factor humano que le subyace, explican las dificultades de obtener certezas sobre esto.

Esta realidad implica reconocer que la verdad es un proceso cuya configuración se genera en tiempos políticos particulares, en los cuales sujetos, estructuras, historias y relaciones tienen lugar. Incluso para llegar a un acto de reconocimiento, es necesario seguir una serie de pasos,

víctimas de ejecuciones extrajudiciales a manos de miembros de la fuerza pública solicitaron participación en las audiencias de versiones en el marco del Caso 003 (Auto N. ${ }^{\circ} 080$ de 2019).

En la CEv, las contribuciones a la verdad realizadas por las víctimas han llamado al reconocimiento de responsabilidad y de aporte a la verdad plena por parte de comparecientes. Ej. la intervención de Ingrid Betancourt en el diálogo "Reflexiones éticas y políticas del secuestro" (CEV, 2020), al cual le siguió el reconocimiento y petición de perdón por parte de los antiguos comandantes de las FARC-EP por ese delito (Calle Aguirre, 2020). 
no siempre lineales, no siempre evolutivos. De hecho, los actores que reconocen la verdad requieren de unos tiempos para verbalizar lo que ocurrió y reconocer responsabilidad. Pasa por las implicaciones para el sujeto que dice la verdad, y los factores (económicos, sociales, jurídicos, institucionales) que determinan qué se dice y en qué momento.

Finalmente, como gran telón de fondo, el tiempo político de la transición les brinda a los tiempos institucionales e individuales contexto y sentido. Es un tiempo de ruptura del proceso histórico, que se abre como paréntesis para que las cosas cambien, se transformen y no se repitan. En el caso colombiano, este tiempo político inició con las negociaciones de paz en 2012, la firma del Acuerdo Final en 2016 y el inicio formal de su implementación programada a tres, quince y veinte años, en los cuales se espera esclarecer la verdad del conflicto. Posiblemente, finalizará con el cierre de los mecanismos cuando hayan cumplido sus objetivos, y se hayan instalado procesos de reconciliación consolidados, lo cual tomará seguramente tres o cuatro décadas.

Así pues, se espera que en este tiempo político se generen los suficientes incentivos para la construcción y consolidación de la paz, y el fortalecimiento de la democracia en el país. Empero, para garantizar el cierre de este paréntesis, las garantías de no repetición son cruciales. Ello incluye la adopción de una solución política al conflicto con el ELN, dando cierre a las disputas armadas con fines políticos.

\subsection{El ¿quién?: la verdad a partir de quién la dice y quién la escucha}

El derecho a la verdad cuenta con una dimensión individual y una dimensión colectiva. La primera recoge el derecho a saber qué ocurrió, y el deber de los comparecientes de revelar la verdad y asumir su responsabilidad frente al Sistema, las víctimas del conflicto y la sociedad. 
La segunda se refiere al derecho de la sociedad a conocer la verdad y el deber del Estado de recordar.

De esta manera, se identifican los actores que intervienen en el proceso: de un lado, quienes revelan la verdad, individuos y grupos partícipes directos e indirectos en las hostilidades, con diversos grados de responsabilidad; y, del otro lado, las víctimas y la sociedad como colectivo, quienes reciben y contestan la verdad para satisfacer su derecho a saber, su derecho a la justicia y su derecho a la no repetición. Surge además un actor intermediario en este proceso: el Estado y su aparato burocrático, como mediador entre las verdades reveladas y recibidas, así como garante del recuerdo y de la no repetición.

\subsubsection{Individuo y colectivo que revela la verdad}

El Acuerdo Final incluye el compromiso de las partes de decir toda la verdad de lo que conocen del conflicto. Este compromiso implica no solamente una presentación individual de lo vivido como autor o testigo, sino también de lo que debió haber conocido, o de lo que fue partícipe como colectivo.

Pero decir la verdad no solamente es llamar a la memoria de forma espontánea y aleatoria. Implica un proceso de ordenación de hechos, fechas, personas y contextos que dan sentido a lo vivido, en muchos casos, aspectos conscientemente olvidados u ocultos. Significa situarse en el presente y, desde allí, con visión en el futuro por lo que a su proyección de vida política, social y familiar le implica, presentar su relato, revelar la verdad. Demanda revisar al pasado, presentarlo lógicamente en sus vivencias, pero también en sus significados y en sus detalles. Detalles requeridos no solo como resultado subjetivo de lo que impactó y quedó grabado en la memoria, sino también de lo que quieren —necesitan- conocer y escuchar las víctimas, las comunidades afectadas y la sociedad. 
El sujeto que revela la verdad -individuo-colectivo- reconstruye esa verdad. La busca en los testimonios y dichos de otros, en la documentación esparcida y apilada en procesos propios y ajenos; la discute y complementa con sus asesores, abogados, compañeros de armas y familiares. Asimismo, quien revela la verdad, está sujeto a los tiempos impuestos por los procesos burocráticos dispuestos por las entidades del SIVJRNR. Los tiempos de las audiencias, los tiempos de los encuentros por la verdad, los tiempos en los que se busca a los desaparecidos. El control de la verdad queda supeditado en buena parte a los tiempos institucionales. Tiempos inscritos en la normatividad basada en el debido proceso en la JEP, y en la metodología de trabajo de la CEV y la UBPD.

\subsubsection{Individuo que recibe y contesta la verdad}

El control sobre los contenidos de la verdad también se ve distribuido entre los responsables y las víctimas, a partir de las continuas reclamaciones de estas últimas sobre su alcance y nivel de detalle. Ello es evidente en la JEP, en donde la participación de las víctimas ha sido ampliamente solicitada y ha implicado un diálogo, no siempre amistoso, sobre lo que se dice, lo que se calla, lo que se oculta, lo que se olvida, lo que se perdió y lo que es imposible recuperar tras la guerra. Los espacios para contestar la verdad, para preguntar, buscar ilustración y mejorar la comprensión de lo dicho están marcados procesalmente. Los momentos para desenmarañar, des-cubrir en lo dicho algo nuevo que dé significado y el control que ostentan las víctimas, son factores limitados por los tiempos institucionales y por las formas del ritual.

El seguimiento estricto de formalidades propias del carácter judicial y la solemnidad requerida por la gravedad de los hechos que se tratarán, se encuentran determinados desde las reglas de procedimiento y de administración de la JEP, quien, a su vez, demanda su propia verdad. En el caso de la CEV y la UBPD, también se plantea un procedimiento para la entrega y recepción de la verdad con menos ritualismo, pero que igual 
requiere de un ejercicio de contrastación riguroso, que responda a los mandatos respectivos de ambas entidades.

Sin embargo, la aceptación, participación y control por parte de las víctimas respecto a los alcances de la verdad en los mecanismos del SIVJRN, termina sujeta a las expectativas generadas desde el Acuerdo Final en torno a la garantía de sus derechos. La percepción en cuanto a los tiempos y relevancia de los aportes de verdad por parte de los comparecientes puede ser fuente de satisfacción o decepción para las víctimas. De hecho, en algunos casos la desconfianza es palpable, pues para muchos hay silencio y complicidad, ${ }^{22}$ mientras que para otros la guerra continúa y este proceso es solo parte de una estrategia para lograr ventajas militares y políticas.

En este punto, el rol del Estado se hace necesario como mediador entre receptores y reveladores de la verdad, desde su obligación de garantizar la no impunidad y el recuerdo de la verdad revelada. Ello implica también la obligación de garantizar las condiciones que permitan, de un lado, la participación de las víctimas en los procesos judiciales y extrajudiciales, y el involucramiento de otros sectores; y, del otro, el conocimiento y difusión de dicha verdad, y su alcance pedagógico, a partir de la protección frente a posibles persecuciones, amenazas y las conflictividades que aún persisten en varias regiones del país.

Así pues, los mecanismos dispuestos por la justicia transicional, al fundarse sobre una base de derecho, aprovechan su potencial para la transformación de "conflictos violentos a conflictos dentro de un marco de paz”, y brindan herramientas para superar estos retos, pues "para eso son las reglas” (Lemaitre, 2021). Sin embargo, es necesaria la coordinación,

22 El Espacio de Litigio Estratégico solicitó a la JEP la apertura de incidentes de incumplimiento por parte del teniente coronel (r) Publio Mejía y el general (r) Mario Montoya, pues considera que no han contribuido con el esclarecimiento de la verdad en torno al Caso 003 sobre "falsos positivos" (Movice, 2020). 
siendo la integralidad del Sistema algo fundamental, pues el componente judicial es insuficiente por sí solo, como lo son también el extrajudicial o la reparación para cumplir con este propósito.

\subsubsection{Colectivo que recibe y contesta la verdad: la sociedad}

Garantizar el derecho a la verdad implica conocer sobre el desarrollo de los hechos asociados al conflicto, las razones que los motivan, su alcance, y el reconocimiento de sus víctimas y responsables. En particular, la sociedad debe conocer los patrones y dinámicas de violencia que tuvieron lugar durante la guerra, y las condiciones que permitieron su reproducción. A partir de este conocimiento es posible entender "las causas del abuso y (...) enfrentarlas: sin el conocimiento preciso de las violaciones del pasado, es difícil prevenir que ocurran nuevamente" (González y Varney, 2013, p. 8). En este punto, la sociedad se convierte en el repositorio colectivo de la verdad contrastada por el SIVJRNR, pues su conocimiento sobre lo ocurrido y su comprensión "más allá de un error", permitirá que se comience a dialogar en torno al "nunca más, y ese nunca más es lo que busca la justicia transicional” (Lemaitre, 2021).

La verdad restaura la dignidad de las víctimas, levanta "salvaguardas contra la impunidad y la negación” (González y Varney, 2013, p. 8) y abre el camino para iniciar procesos de reconciliación y de reconstrucción de los vínculos de confianza, al interior y entre comunidades, rotos durante la guerra. Desde una apuesta de construcción conjunta, en Colombia se espera fomentar el diálogo entre versiones desde los diversos lugares de enunciación de actores y sectores. El Estado, como garante, tiene el deber de recordar y de socializar los hallazgos del proceso de búsqueda de la verdad, así como de adoptar medidas para evitar la repetición de las atrocidades de la guerra.

Sin embargo, surgen dudas en torno al alcance social y reparador de esta verdad. Del espacio que le abra la sociedad para acogerla, soportarla, avergonzarse de ella, no excusarla ni justificarla y reconocerse 
como copartícipe, dependerá mucho su poder transformador. El reto de la verdad será la creación de puentes que favorezcan la convivencia en todo el territorio, en especial, ante un contexto de continuidad de la violencia armada en los territorios y de polarización política. Ello tiene sentido en una comprensión restaurativa de la justicia que "no solo busca involucrar a todas las partes de un conflicto, sino que también pretende la restauración de los valores morales, la dignidad de las personas y la equidad social” (Díaz Colorado, 2008, p. 121).

Finalmente, de la capacidad que tenga la sociedad de convertir la verdad en acción y el recuerdo en deber, dependerá el futuro de la democracia y su consolidación. "Recordar es una tarea que todos tenemos como sociedad” (Marré, citado en CEv, 2019b, El camino, párr. 2).

\section{Reflexiones finales}

En el presente artículo se ha desarrollado una propuesta exploratoria para la comprensión del derecho a la verdad y la forma en que este se experimenta en la justicia transicional colombiana como una construcción ética, jurídica, política y fáctica, en el marco de un proceso relacional, multidireccional y polifónico que evoluciona en el tiempo.

Ello es visible a través de la revisión del carácter institucional de la verdad, las funciones que cumple, los tiempos que requiere y finalmente los actores que involucra, en un ejercicio intersubjetivo y de contrastación, que tiene como fin la garantía de este derecho y la dignificación de las víctimas. A lo largo de este análisis se hace visible un carácter instrumental y racional de este derecho, propio de su codificación normativa y su materialización burocrática. Asimismo, el carácter axiológico y moral vinculado a las expectativas que existen en torno al alcance de esta verdad, como sustento de un modelo de justicia que restaure la dignidad de las víctimas del conflicto y contribuya a máximas como la convivencia, la reconciliación y la no repetición. 
La verdad que el SIVJRNR ofrecerá a las víctimas será, de un lado, producto de una tarea institucional conjunta, que requiere de un ejercicio de investigación y contrastación de fuentes y testimonios, así como de reconocimiento y promoción de encuentro entre actores. La verdad factual, social y narrativa que derive de este ejercicio, será clave para el proceso de construcción de una verdad reparadora que cumpla con la función última de dignificación y construcción de paz y reconciliación.

De otro lado, la verdad resultante de un proceso polifónico y que evoluciona a través del tiempo y las experiencias paralelas de actores, instituciones y el ejercicio político, deberá tener un carácter social gracias a los principios dialógicos que rigen el SIVJRNR, así como reparador desde su valor curativo para las víctimas y la sociedad entera. Del reconocimiento sobre lo ocurrido durante la guerra y el compromiso de la sociedad con la construcción de paz, dependerá ese alcance "reparador" de vínculos y relaciones que sustenta la reconciliación y la no repetición.

Finalmente, en este artículo también se quiso plantear algunas reflexiones sobre la verdad, a muy poco tiempo de la presentación del informe final de la CEV. Recordar las múltiples funciones de la verdad; reconocer que es compleja, ondulante e intermitente; y entender que tiene tiempos y no es unívoca, son aspectos que pueden contribuir a asumir los retos que impondrá la lectura del informe. En un contexto nacional de alta violencia, de guerras sin normas y de antagonismos hondamente arraigados, el informe final de la CEV llegará para interpelar a toda la sociedad por la barbarie vivida-permitida y negada hasta el momento, pero también para generar puentes y comenzar a cerrar los ciclos de violencia. Prepararse para leerlo, y tener abierta la mente y el corazón para entenderlo, es una tarea urgente de todos los colombianos.

\section{Referencias}

Auto N. ${ }^{\circ} 080$ de 2019 [Jurisdicción Especial para la Paz]. Decidir recurso de reposición interpuesto en contra del Auto N. ${ }^{\circ} 062$ del 9 de mayo de 2019. 
Mayo 28 de 2019. Recuperado de https://relatoria.jep.gov.co/documentos/ providencias/1/1/Auto_SRVR-080_28-mayo-2019.pdf

Auto N. ${ }^{\circ} 19$ de 2021, Caso N. ${ }^{\circ} 01$ [Jurisdicción Especial para la Paz]. Toma de rehenes y graves privaciones de la libertad cometidas por las FARC-EP. Enero 26 de 2021.

Berman, Sheri. (2019). Democracy and Dictatorship in Europe. From the Ancien Régime to the Present Day. Oxford: Oxford University Press.

Calle Aguirre, María Clara. (27 de septiembre de 2020). Colombia: el poder de las víctimas en la implementación del Acuerdo de Paz. Recuperado de https://www.france24.com/es/20200927-colombia-poder-victimas-implementacion-acuerdo-de-paz-jep-comision-verdad

Comisión de la Verdad. (7 de noviembre de 2018a). Una mirada a las comisiones de la verdad en el mundo y a la de Colombia. Recuperado el 21 de enero de 2021 de https://comisiondelaverdad.co/actualidad/noticias/una-mirada-a-las-comisiones-de-la-verdad-en-el-mundo-y-a-lanuestra\#: :text = Las \% 20comisiones \% 20de \% 20la \% 20verdad \% 20se \% 20 conciben \% 20como \% 20un \% 20mecanismo,escenarios \% 20de \% 20paz \% 20 o \%20democracia

Comisión de la Verdad. (18 de diciembre de 2018b). Guía de presentación de casos ante la Comisión de la Verdad. Recuperado de https://www.google. $\mathrm{com} / \mathrm{url}$ ? sa $=\mathrm{t} \& \mathrm{rct}=\mathrm{j} \& \mathrm{q}=\& \mathrm{esrc}=\mathrm{s} \&$ source $=$ web\& $\mathrm{cd}=\& \mathrm{cad}=\mathrm{rja} \& u a c t=$ $8 \&$ ved $=2$ ahUKEwj90t-s1-ruAhXyBBAIHUGDAAwQFjACegQIAhAC\&url = https \% 3A \% 2F\%2Fcomisiondelaverdad.co \%2Fimages \% 2Fguia-presentacion-casos-comision-verdad.pdf\&usg = AOvVaw0DlBgcEoERJmj8dhh8AY $\mathrm{mk}$

Comisión de la Verdad. (5 de marzo de 2019a). "La búsqueda de la verdad es de suma importancia para construir democracias sólidas": Boaventura de Sousa. Recuperado de https://comisiondelaverdad.co/actualidad/noticias/boaventura-de-sousa-busqueda-de-la-verdad-es-importancia-paraconstruir-democracias-solidas

Comisión de la Verdad. (13 de mayo de 2019b). "Recordar es una tarea que todos tenemos como sociedad". Recuperado de https://comisiondelaverdad. co/actualidad/noticias/casa-verdad-cucuta-recordar-es-una-tarea-que-todos-tenemos-como-sociedad 
Comisión de la Verdad. (2019c). Escuchar, reconocer y comprender: lineamientos metodológicos de la Comisión de la Verdad. Bogotá D.C.: Autor.

Comisión de la Verdad. (Enero-diciembre de 2019c). Informe de Gestión. Comisión para el esclarecimiento de la verdad, la convivencia y la no repetición. Recuperado de https://comisiondelaverdad.co/images/Informe_de_gestion_Institucional_2019VF.pdf

Comisión de la Verdad. (14 de septiembre de 2020b). Reflexiones éticas y políticas sobre el secuestro. Ingrid Betancourt Pulecio habla con la Comisión de la Verdad. [Archivo de video]. YouTube. Recuperado de https://www. facebook.com/ComisionVerdadC/videos/254204195756648

Comisión de la Verdad. (30 de enero 2021a). Informe de Gestión. Comisión para el esclarecimiento de la verdad, la convivencia y la no repetición. Período Enero-Diciembre 2021. Recuperado de https://comisiondelaverdad.co/ actualidad/noticias/informe-de-gestion-de-junio-a-diciembre-de-2020

Comisión de la Verdad. (9 de febrero de 2021b). ¿Cómo puedo aportar al esclarecimiento de la verdad? Recuperado de https://comisiondelaverdad.co/ la-comision/como-puedo-aportar-al-esclarecimiento-de-la-verdad

Comisión de la Verdad. (s.f.). Preguntas frecuentes. ¿Tiene preguntas sobre la Comisión de la Verdad? Recuperado de https://comisiondelaverdad.co/ la-comision/preguntas-frecuentes

Comisión de la Verdad y Dejusticia. (2019). La Comisión de la Verdad y el Sistema Integral de Verdad, Justicia, Reparación y No Repetición: conceptos clave para su mandato. Bogotá: Centro de Estudios de Derecho, Justicia y Sociedad, Dejusticia.

Decreto 700 de 2017 [Presidencia de la República]. Por el cual se precisa la posibilidad de interponer la acción de hábeas corpus en casos de prolongación indebida de la privación de la libertad derivados de la no aplicación oportuna de la Ley 1820 de 2016 y el Decreto-ley 277 de 2017. Mayo 2 de 2017. DO. No 50.221.

Decreto 706 de 2017 [Presidencia de la República]. Por el cual se aplica un tratamiento especial a los miembros de la Fuerza Pública en desarrollo de los principios de prevalencia e inescindibilidad del Sistema Integral de Verdad, Justicia, Reparación y se dictan otras disposiciones. Mayo 3 de 2017. DO. $\mathrm{N}^{\mathrm{o}} 50.222$. 
Decreto Ley 277 de 2017 [Presidencia de la República]. Por el cual se establece el procedimiento para la efectiva implementación de la Ley 1820 del 30 de diciembre de 2016 "por medio de la cual se dictan disposiciones sobre amnistía, indulto y tratamientos penales especiales y otras disposiciones”. Febrero 17 de 2017. DO. N 50.150.

Decreto Ley 588 de 2017 [Presidencia de la República]. Por el cual se organiza la Comisión para el Esclarecimiento de la Verdad, la Convivencia y la No Repetición. Abril 5 de 2017. DO. N. ${ }^{0} 50.197$.

Decreto Ley 589 de 2017 [Presidencia de la República]. Por el cual se organiza la Unidad de Búsqueda de Personas dadas por desaparecidas en el contexto y en razón del conflicto armado. Abril 5 de 2017. DO. No 50.197.

Díaz Colorado, Fernando. (2008). La justicia transicional y la justicia restaurantica frente a las necesidades de las victimas. Umbral Científico, (12), 117-130. Recuperado de https://www.redalyc.org/articulo. oa? id $=30401210 \&$ iCveNum $=10097$

Escuela Nacional Sindical. (7 de julio de 2019). ¿Cuál es la diferencia entre memoria y verdad? El Sindicalismo Cuenta [Archivo de video]. YouTube. Recuperado de https://www.youtube.com/ watch?v $=1$ p66stxeXWk\&ab_channel = EscuelaNacionalSindical

Gobierno de Colombia y FARC-EP. (7 de junio de 2014). Declaración de Principios para la discusión del punto 5 de la agenda: "Víctimas" - 7 de junio [Archivo de video]. YouTube. Recuperado de https://www.youtube.com/ watch?v=6P_Pm1dYrWA

González, Eduardo y Varney, Howard (Edits.). (2013). En busca de la verdad. Elementos para la creación de una comisión de la verdad eficaz. Nueva York: Centro Internacional para la Justicia Transicional.

González-Salzberg, Damián A. (2008). El derecho a la verdad en situaciones de post-conflicto bélico de carácter no-internacional. International Law. Revista Colombiana de Derecho Internacional, 6(12), 435-468.

Hartog, François. (2012). El tiempo de las víctimas. Revista de Estudios Sociales, (44), 12-19. Recuperado de http://www.scielo.org.co/scielo. php?script $=$ sci_arttext\&pid $=$ S0123-885X2012000300002\&lng $=$ en\&tlng $=$ es 
International Center for Transitional Justice [ICTJ]. (31 de mayo de 2017). La Comisión de la Verdad (CEV): fundamental para las víctimas y la transición en Colombia. Recuperado de https://www.ictj.org/es/news/ comision-verdad-cev-amicus-colombia

Jurisdicción Especial para la Paz [JEP]. (3 de marzo de 2020a). Comunicado 028. La JEP recibe 272 observaciones de víctimas a las versiones de la extinta guerrilla de las FARC-EP dentro del caso de secuestro. Recuperado de https://www.jep.gov.co/Sala-de-Prensa/Paginas/La-JEP-recibe-272-observaciones-de-v \% C3\% ADctimas-a-las-versiones-de-la-extinta-guerrilla-delas-Farc-EP-en-el-caso-de-secuestro.aspx

Jurisdicción Especial para la Paz. (2020b). Informe Estadistico. Corte del I semestre año 2020. Recuperado de https://www.jep.gov.co/rendiciondecuentas/Informes \% 202020/Informe \% 20estadi \% CC \% 81 stico \% 20I\% 20Semestre.pdf

Ley 975 de 2005. Por la cual se dictan disposiciones para la reincorporación de miembros de grupos armados organizados al margen de la ley, que contribuyan de manera efectiva a la consecución de la paz nacional y se dictan otras disposiciones para acuerdos humanitarios. Julio 25 de 2005. DO. No 45.980 .

Ley 1448 de 2011. Por la cual se dictan medidas de atención, asistencia y reparación integral a las víctimas del conflicto armado interno y se dictan otras disposiciones. Junio 10 de 2011. DO. N. ${ }^{\circ} 48.096$.

Ley 1820 de 2016. Por medio de la cual se dictan disposiciones sobre amnistía, indulto y tratamientos penales especiales y otras disposiciones. Diciembre 30 de 2016. DO. No 50.102 .

Ley 1922 de 2018. Por medio del cual se adoptan unas reglas de procedimiento para la Jurisdicción Especial para la Paz. Julio 18 de 2018. DO. No 50.658.

Ley 1957 de 2019. Estatutaria de la Administración de Justicia en la Jurisdicción Especial para la Paz. Junio 6 de 2019. DO. N. ${ }^{\circ} 50.976$.

Makazaga, Iñaki. (21 de junio de 2017). "En Colombia la verdad y la memoria deben estar al servicio de la paz". Recuperado de https://elpais.com/elpais/2017/06/15/planeta_futuro/1497540230_794573.html 
Moreno, María Camila. (31 de mayo de 2017). Concepto técnico sobre el Decreto 588 del 5 de abril de 2017, por medio de la cual "se organiza la Comisión para el Esclarecimiento de la Verdad, la Convivencia y la No Repetición”. Recuperado de https://www.ictj.org/sites/default/files/ICTJ-COL-AmicusCEV-Final.pdf

Movimiento Nacional de Víctimas de Crímenes de Estado [Movice]. (30 de septiembre de 2020). Víctimas solicitan expulsar a Mario Montoya y Publio Hernán Mejía de la Jep. Recuperado de https://movimientodevictimas.org/victimas-solicitan-expulsar-a-mario-montoya-y-publio-hernan-mejia-de-la-jep/

Pérez, Juan Pablo. (4 de febrero de 2021). "No fueron 'errores' que se cometieron, fueron crímenes de guerra y de lesa humanidad": Julieta Lemaitre. [Entrevista]. Recuperado de https://lasillavacia.com/no-fueron-errores-secometieron-fueron-crimenes-guerra-y-lesa-humanidad-julieta

Resolución N. ${ }^{\circ} 075$ de 2019 [Comisión de la Verdad]. Por la cual se fijan los criterios para la certificación de la participación de comparecientes ante la Jurisdicción Especial para la Paz que se presentan ante la Comisión de la Verdad y aportan en la ruta de esclarecimiento de la verdad. Agosto 8 de 2019.

Riaño, Pilar y Uribe, María Victoria. (2017). Construyendo memoria en medio del conflicto: el Grupo de Memoria Histórica en Colombia. Revista de Estudios Colombianos, (50), 9-23.

Rincón, Tatiana. (2010). Verdad, justicia y reparación. La justicia de la justicia transicional (Primera ed.). Bogotá, D. C.: Editorial Universidad del Rosario.

Salazar, Philippe-Joseph. (2015). La reconciliación como modo de vida ética de la república. En Claudia Hilb, Philippe-Joseph Salazar y Lucas Martín (Edits.), Lesa humanidad: Argentina y Sudáfrica: reflexiones después del Mal (pp. 161-180). Madrid: Katz.

Samudio, Vera. (2019). Los derechos de las víctimas en el Acuerdo Final: una Ruta para la Paz (Documento inédito). En Construcción de Paz en Colombia: Desafíos del Post Acuerdo. Bogotá D.C.

Samudio, Vera. (Enero-junio de 2020). La implementación del Acuerdo de Paz en tiempos de pandemia. Revista Cien Días. Recuperado de https://www.revistaciendiascinep.com/home/ la-implementacion-del-acuerdo-final-en-tiempos-de-pandemia/ 
Secretaría Técnica del Componente Internacional de Verificación CINEP/PPPCERAC. (2021). Octavo informe de verificación de la implementación del Acuerdo Final de Paz en Colombia. Recuperado de https://www.cinep. org.co/Home2/component/k2/864-octavo-informe-de-verificacion-de-laimplementacion-del-acuerdo-final-de-paz-en-colombia.html.

Tapia Mealla, Luis. (2009). Los espacio-tiempo políticos. En Luis Tapia Mealla, Pensando la democracia geopolíticamente. La Paz: Clacso.

Truth and Reconciliation Commission. (1998). Volume One. Truth and Reconciliation Commission of South Africa Report. Recuperado de https://www. justice.gov.za/trc/report/finalreport/Volume\%201.pdf

Unidad de Búsqueda de Personas dadas por Desaparecidas [UBPD]. (12 de mayo de 2020a). UBPD ha recibido 174 aportes voluntarios de información para la búsqueda. Recuperado de https://www.ubpdbusquedadesaparecidos. co/actualidad/ubpd-ha-recibido-174-aportes-voluntarios-de-informacionpara-la-busqueda/

Unidad de Búsqueda de Personas dadas por Desaparecidas. (5 de noviembre de 2020b). Conozca el Informe de actividades de la Unidad de Búsqueda de Personas dadas por Desaparecidas. Recuperado de https://www.ubpdbusquedadesaparecidos.co/actualidad/conozca-el-informe-de-actividades-dela-unidad-de-busqueda-de-personas-dadas-por-desaparecidas/

Unidad para la Atención y Reparación Integral de Víctimas [UARIV]. (1 de enero de 2021). Registro Único de Víctimas. Recuperado de https://www.unidadvictimas.gov.co/es/registro-unico-de-victimas-ruv/37394

Uprimny, Rodrigo y Saffon, María Paula. (2006). Verdad judicial y verdades extrajudiciales: la búsqueda de una complementariedad dinámica. Pensamiento Jurídico, (17), 9-36. 